\title{
The interpretation of external arguments ${ }^{1}$ \\ Jim Wood and Alec Marantz.
}

\section{Introduction}

The striking parallels across languages in the syntactic expression of "argument structure" broadly construed has led within generative grammar, at least since Generative Semantics, to generative theories that demand a kind of transparent reflection of argument structure in underlying syntactic representations. This trend is reflected in approaches oriented around thematic roles, such as those that adopt some version of UTAH ("Uniformity of Theta Assignment Hypothesis"), as well as event-structure oriented approaches like Ramchand's (2008, this volume) in which, in a sense, event structure is underlying syntactic structure. An alternative approach attributes the relative uniformity of the expression of argument structure to the principles that interpret syntactic structure semantically; here, syntax is truly autonomous, with the atoms of syntactic representations and their relations carrying no semantic values. On this alternative approach, we might expect that the same meanings could be expressed by different syntactic structures and that the same syntactic structures might express different meanings.

Recent work from Myler and Bruening illustrate this approach in different though related domains. Myler (2014) argues that the expression of possession in predication (as in "I have a book") varies cross-linguistically in such a way that the same meanings are constructed by different syntactic processes in different languages, without being related to a single syntactic structure. Bruening (2010) argues in the same vein that the double object and the to-dative expression of transfer of possession in English involve different syntactic structures, not transformationally related structures. (Here he follows a long tradition in the literature but provides a contemporary demolition of the alternative proposals.)

While Myler and Bruening support the autonomy of syntax by demonstrating that syntactic structures may be semantically ambiguous and semantic structures may find alternative syntactic representations, in this chapter we will extend the argument to the inventory of syntactic heads. We will argue that syntactic heads crucially involved in the interpretation of argument structure - heads like v, voice, $\mathrm{p}$ and appl - are subject to contextual allosemy at the semantic interface. Each such head may have a particular range of meanings, including a null (expletive) meaning, depending on the syntactic context. Once syntactic heads are absolved from the necessity of carrying certain features relevant to their interpretation explicitly - when the features are rather computed contextually at the point of semantic interpretation - we can develop a sparse inventory of functional heads for the syntax.

For example, in theories that separate a verbalizing category head $\mathrm{v}$ from the verbal root, the little $v$ node is observed to vary in interpretation across verb categories, in particular alternating between what might be labeled $\mathrm{v}_{\mathrm{BECOME}}$ for inchoative sentences like "the door opened" and $\mathrm{v}_{\text {DO }}$ (or $\mathrm{v}_{\text {CAUSE }}$ ) for transitive sentences like "John opened the door." The alternation here is a reflection of Burzio's Generalization: external argument and transitivity lead to the $\mathrm{v}_{\mathrm{DO}}$ interpretation and no external argument and intransitivity lead to the $\mathrm{v}_{\mathrm{BECOME}}$ interpretation. If the interpretation of the $\mathrm{v}$ correlates with the syntax, then there is no motivation to include a syntactic feature related to the difference in interpretation, over and above any syntactic features related to the syntactic projection of an external argument and syntactic transitivity.

\footnotetext{
${ }^{1}$ We are grateful to Anton Ingason, Einar Sigurðsson, Heidi Harley, Neil Myler, two reviewers and the editors of this volume for comments on this chapter, and Itamar Kastner and the Roots IV participants for discussion of the ideas presented here.
} 
In this chapter, we present an account of the heads that add participants to events. Within current theories, these heads are usually identified as voice, appl, and prepositions, as well as little $\mathrm{v}$ for some linguists, where the causative little $\mathrm{v}$ head might introduce an agent or causer. We will follow Pylkkänen (2008), Harley (2013, this volume) and Legate (2014) among others (see e.g. Sundaresan and McFadden, this volume), in arguing that little v does not, by itself, introduce an argument, so our account will focus primarily on the voice, appl, and prepositional heads. The empirical focus of the chapter revolves around Icelandic figure reflexives, Japanese adversity causatives, and possessor raising constructions.

The chapter is organized as follows. In section 2, we lay out our basic proposal, outlining the syntactic and semantic features of argument-introducing heads. In section 3 , we present an analysis of Icelandic figure reflexives, which illustrates one basic process that will be crucial to the analysis of possessor raising and Japanese adversity causatives. In section 4, we develop the account of Japanese adversity causatives. This will involve an analysis of predicate possession, the internal argument of change-of-state (anti)causatives, and possessor raising. Section 5 concludes.

\section{The proposal}

We begin by making a distinction between little $\mathrm{v}$, on the one hand, and voice, appl and prepositions, on the other. As we will discuss in more detail in section 4, little $v$ has the syntactic function of verbalizing category-neutral roots, and serves as the semantic locus for a variety of interpretive processes which will be discussed throughout. What little $\mathrm{v}$ does not do is introduce argument DPs syntactically; nor does it serve as the semantic locus for the thematic interpretation of DPs. Morphologically, however, the spellout of little $\mathrm{v}$ can be sensitive to the presence of an external argument. For example, in languages like Japanese, the causative-inchoative alternation is often marked with a ("lexical") "causative" affix on the transitive variant (see Harley this volume, Shimura and Wurmbrand this volume). As we will discuss further below, this "causative" affix does not always imply causative semantics. What the morphology is telling us, in this case, is not that the semantics involves causativity, but that the syntax involves an external-argumentintroducing voice head in a transitive construction. That is, the causative suffix is the contextually-determined spellout of $\mathrm{v}$ in the context of an external-argument-introducing voice head.

In terms of argument-introducing heads, we are left with five potentially distinct heads:
a. voice introduces the external arguments of vPs (often agents)
b. low appl introduces an argument related to a DP
c. little $\mathbf{p}$ introduces the external arguments of PPs (figures)
d. prepositions introduce non-core arguments in a manner syntactically distinct from high appl
e. high appl introduces a non-core argument

We propose that these five heads can be reduced to one single argument introducer, which we will refer to as $i^{*}$, in distinct syntactic contexts. The differences between the apparently different uses of $i^{*}$ stem from rules that are sensitive to the syntactic context in which it occurs.

Our proposal is thus that from a syntactic perspective, there is one argument-introducing head, which is unspecified categorially and selects for a syntactic constituent of category D (selection for D encodes the "argument introducing" property that characterizes these heads; see Schäfer 2008, this volume). Following Bruening (2012), we annotate selectional features in 
brackets, so $\mathrm{P}_{[\mathrm{S}: \mathrm{D}]}$ is a head of category $\mathrm{P}$ that selects $(\mathrm{S})$ for a constituent of category $\mathrm{D}$. Since $i^{*}$ is categorially unspecified, it does not start out with a categorial feature, but is rather something like $\left\{[\mathrm{CAT}:[],[\mathrm{S}: \mathrm{D}]\}\right.$, where the underscore indicates an unvalued CAT(egory) feature; $i^{*}$ is simply an convenient notation for this feature bundle. We should note immediately that the selectional feature [S:D] shouldn't be understood as a necessary condition on Merge, as will be clear below; it is a feature that can, but need not, trigger Merge with a constituent of category D. In the context of the present study, it would be descriptively accurate to say that a selectional feature cannot be checked until the categorial feature is valued. In cases where the selectional feature is checked and the categorial feature is unvalued, the categorial feature will automatically get the value "P". This, as we will see, is how prepositions are built.

There are essentially three factors that interact to determine the syntactic and semantic properties of $i^{*}$. First, $i^{*}$ can merge with a variety of syntactic categories, so its interpretation can be read off of its structural position. Second, the categorial feature of $i *$ may be valued by the categorial feature of the first or the second constituent it merges with. Third, lexical roots may adjoin to $i^{*}$; when they do, they will affect the interpretation of $i^{*}$ (as well as certain syntactic properties of $i^{*}$, as we will see).

The '*'-notation on $i *$ indicates a crucial syntactic property of this head, one which does not follow automatically from its other syntactic and semantic functions. Essentially, $i^{*}$ closes off the extended projection of the first constituent it merges with. If that constituent is a lexical root, it closes off the extended projection of the lexical root (to the extent that lexical roots have extended projections; nothing in the present paper hinges on answering the question of whether roots may take arguments or otherwise project). If that constituent is an XP, then it closes off the extended projection of that XP. We will notate this by projecting the '*' only onto the node that immediately dominates $i^{*}$. Although this is stipulative, it is definitional-stipulative, telling us something about the basic properties of the system. We leave it to future research to determine whether the stipulation would follow directly from a slightly different general architecture of grammar.

As a final note on notation, we will generally label phrasal constituents as XP in the familiar way, without necessarily committing to the idea that phrasal nodes are actually labeled in this way by the grammar in any sense that matters for the syntax. However, c-selection does require the notion of a head, and thus at least the determination of an asymmetry between merged constituents. Much of the work apparently done by phrasal constituent labeling here could be recast in terms of structural conditions revolving around the head (cf. Collins 2002).

Let us now illustrate how these assumptions derive the basic interpretations of argumentintroducing heads. First, we can define the basic heads - little p, voice and low appl(icative) - as follows:
a. Little $\mathrm{p}$ (figures): Bare $i *$ that merges with PP.
b. Voice (agents): Bare $i *$ that merges with vP.
c. Low appl (possessors): Bare $i *$ that merges with DP.

When $i^{*}$ merges with these constituents, its categorial feature is valued to match that of its complement. So when $i^{*}$ merges with a vP, it becomes $\{[\mathrm{CAT}: \mathrm{v}],[\mathrm{S}: \mathrm{D}]\}$. Since it is a head merging with an XP, it will be the label of the resulting constituent: essentially $v^{*}[\mathrm{~S}: \mathrm{D}]$. It projects its selectional feature, so that the newly formed $v^{*} \mathrm{P}[\mathrm{S}: \mathrm{D}]$ c-selects for something of category $\mathrm{D}$. 
Note that this system places voice within the extended projection of $\mathrm{v}$; the $*$ notation indicates that voice also closes this projection.

The interpretive differences between what were formerly understood as distinct heads are now understood as contextually-determined interpretation rules. We illustrate this for agents and figures in (4) (returning to possessors in section 4).
a. $\llbracket i * \rrbracket \leftrightarrow \lambda \mathrm{x} \lambda \mathrm{s}$. FIGURE(x,s)/
(locative PP)
b. $\llbracket i * \rrbracket \leftrightarrow \lambda \times \lambda$ e. AGENT(x,e)/ (agentive vP)

Voice, little p and low appl, then, are three distinct "uses" of the same syntactic head. We will see below that these heads are indeed syntactically and semantically similar in a way that supports their unification.

(Big) $\mathrm{P}$ and high appl are different, in that they seem to introduce their own thematic semantics in a way that does not depend on the semantics of the element they attach to. According to our proposal, this is because $\mathrm{P}$ and high appl are the names we give to $i *$ with a lexical root adjoined to it. In the cases of interest here, the lexical roots of prepositions adjoin to $i^{*}$ to form a DP-selecting preposition. When this $i *$ merges with a DP, it selectional feature may or may not be checked. When it is checked, the categorial feature of $i *$ is automatically valued as P. This is, then, a configurational definition of a preposition: a preposition is an $i^{*}$ that checks its selectional feature without valuing its categorial feature. ${ }^{2}$ The lexical semantics of the overall preposition stems from the root. They can be determined by the root directly, or else as contextuallyspecified interpretations of $i *$ in the context of the root. Thus, in is different from on because the root $\sqrt{ }$ IN has or conditions different semantics from the root $\sqrt{ }$ ON (e.g. container vs. surface). The structure of a pP small clause such as the car on the road is shown in (5).

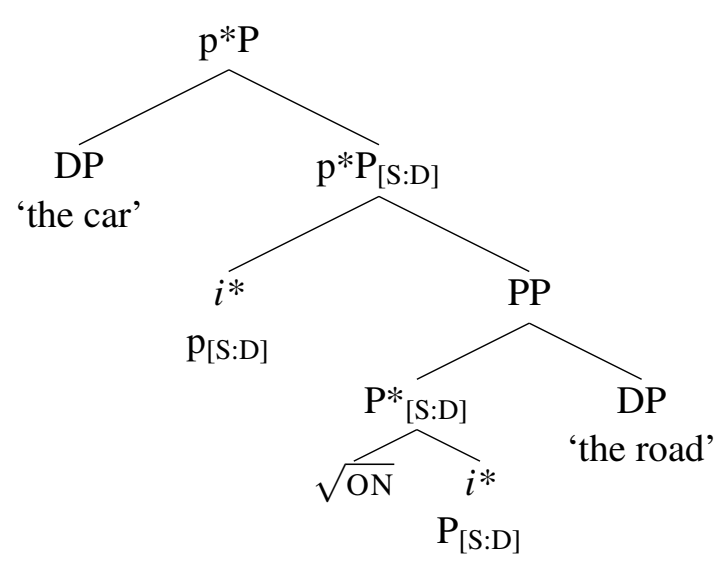

First, $\sqrt{ }$ oN adjoins to $i^{*}$. This $i^{*}$ merges with a DP the road, satisfying the selectional [S:D] feature; at this point, the categorial feature of $i^{*}$ is valued as "P", so it projects a PP. Then, another $i^{*}$ merges with this PP, which values $i *$ 's categorial feature as " $\mathrm{p}$ ", resulting in $\mathrm{p}_{[\mathrm{S}: \mathrm{D}]}$. Since the selectional [S:D] feature has not been checked, the resulting constituent is $\mathrm{p}^{*} \mathrm{P}_{[\mathrm{S}: \mathrm{D}]}$, i.e. a $\mathrm{pP}$ that c-selects a constituent of category $\mathrm{D}$. Finally, the $\mathrm{DP}$ the car merges with the $\mathrm{p}^{*} \mathrm{P}_{[\mathrm{S}: \mathrm{D}]}$ to form a

\footnotetext{
${ }^{2}$ We might take of in its semantically vacuous uses to be an instance of $i^{*}$ without a root adjoined to it merging with a DP and checking its selectional feature. We set aside, for now, a more detailed investigation of this possibility.
} 
$\mathrm{p} * \mathrm{P}$. The interpretive rule in (4a) applies, and the car is interpreted as a figure of the spatial relation introduced by $o n$.

In general (with a principled exception to be discussed below), what the $i^{*}$ head does is merge with $\mathrm{X}$, and then with $\mathrm{Y}$, and then assign to $\mathrm{Y}$ the thematic role implied by $\mathrm{X}$. If $\mathrm{X}$ is a lexical root, then it assigns to $\mathrm{Y}$ the role implied by that root. In (5) above, the lower $i^{*}$ merges with $\sqrt{ }$ ON and then a DP and assigns to the DP the role implied by $\sqrt{ }$ ON (so the DP is interpreted as a surface). ${ }^{3}$ The higher $i^{*}$ merges with a PP and then a DP, and assigns to the DP the role implied by the PP (namely, the figure role implied by the overall spatial semantics of the $\mathrm{pP}$ ).

This account of prepositions leads us directly to our account of high appl. High appl is like a root-adjoined $i^{*}$ in that the thematic role ( $\theta$-role) it ultimately assigns to a DP (in its specifier) is not implied by the vP semantics. For example, a vP like hold the bag may imply an agent before an agent is projected syntactically just by virtue of what it means to hold a bag. But the same would not hold for a beneficiary; there may be a beneficiary of a bag-holding event, but there is nothing about bag-holding that in itself implies the presence of a beneficiary. So when a high appl merges with a vP, it cannot be the case that the $\theta$-role it assigns comes from that $\mathrm{vP}$. Instead, the range of $\theta$-roles available to a high appl tends to be drawn from the kinds of $\theta$-roles that can also be introduced by prepositions: beneficiaries (English for), maleficiaries (English on), locations (English in), etc. Finally, high appl differs from voice in that it does not "close off" the $\mathrm{vP}$ projection; by merging first with a root, it closes off the projection of the root, and does not "project" its closing-off star to the appl head it creates. Essentially, a high applP is just like a $\mathrm{vP}$; anything that can select for a vP can select for a high applP. There is no necessary categorial difference between a high applP and a vP (Harley 2013:50,fn.23).

Following recent work (Acedo-Matellán 2010; Haselbach and Pitteroff 2014), prepositions can be like other lexical categories in consisting of a category-neutral root and a categorydetermining functional head. We want to say that adjoining a root to $i^{*}$ can ultimately lead to a $\mathrm{P}$ and a PP. But as noted above, this happens when the root-adjoined $i^{*}$ checks its selectional feature by merging with DP. Another possibility is that $i^{*}$ does not check its selectional feature on first merge, but instead values its categorial feature. If the root-adjoined $i^{*}$ merges with a $\mathrm{vP}$, its categorial feature is valued as " $\mathrm{v}$ " and its selectional feature is projected onto the resulting constituent. However, since this is the second merge, the resulting vP is just $\mathrm{vP}_{[\mathrm{S}: \mathrm{D}]}$, not $\mathrm{v} * \mathrm{P}_{[\mathrm{SS:D]}}$. The $\theta$-role implied by the root will then be assigned not to the vP, but to the DP specifier (a conclusion which follows from how the compositional semantics works, as will be shown below). We can now distinguish what are traditionally called prepositions and high appl heads in the following way: ${ }^{4}$

d. Big P (prepositions): root-adjoined $i *$ with selectional feature checked by complement. e. High appl (affectees): root-adjoined $i^{*}$ with selectional feature not checked by complement.

High appl, then, instantiates the most complex of the $i^{*}$ configurations. It takes three instances of merge to build it: merge with a root that determines the thematic role, followed by merge with a

\footnotetext{
${ }^{3}$ Here we follow the insights of Svenonius $(2003,2007)$ in assuming that in figure-ground oppositions (Talmy 1985), figures are true external arguments, analogous to agents in verb phrases, whereas grounds get a variety of interpretations, just like themes in verb phrases.

${ }^{4}$ In principle, a low appl could also be root-adjoined, as long as its DP complement values its categorial feature instead of checking its selectional feature. We leave this possiblity for future research.
} 
vP that determines its category, and finally merge with a DP that ultimately bears the thematic role determined by the root.

Consider how this derives the similarities between a beneficiary PP and a beneficiary high appl. A beneficiary PP like for Mary, adjoined to vP in the sentence John held the purse for Mary, would have the structure in (7).

(7)

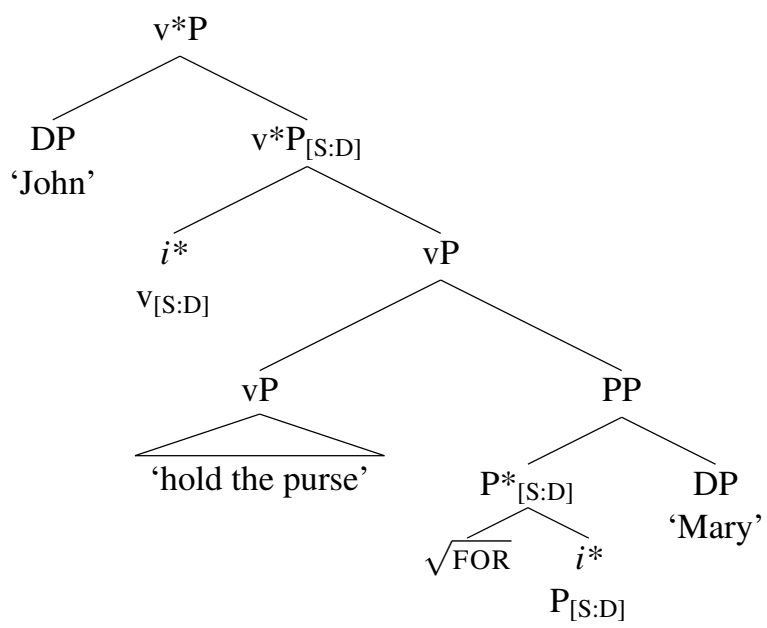

The PP for Mary is formed in the same manner as the PP on the road was in (5) above. This constituent then adjoins to the vP hold the purse. Next, the agent is introduced: $i *$ merges with vP, valuing its categorial feature as $\mathrm{v}$, and projects a $\mathrm{v}^{*} \mathrm{P}_{[\mathrm{S}: \mathrm{D}]}$, i.e. a vP structure that c-selects for a DP. The external-argument DP John merges with this structure, resulting in a complete $\mathrm{V} * \mathrm{P}$.

High appl is just like the preposition for except that instead of merging with DP and then $\mathrm{vP}$, it merges with $\mathrm{vP}$ and then DP. In this system, the difference stems from when the selectional feature of $i *$ is checked, which in turn reflects how the categorial feature is valued. The structure is illustrated in (8).

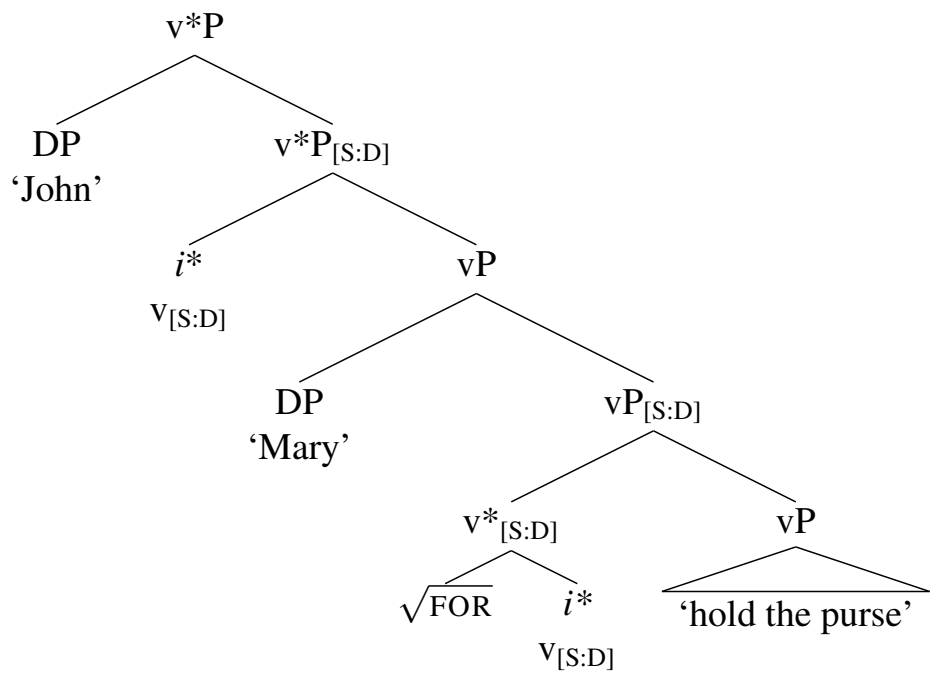


In this structure, $i^{*}$ merges first the lexical root. Second, it merges with a vP, valuing its categorial feature as $\mathrm{v}$, and projecting a $\mathrm{vP}_{[\mathrm{S}: \mathrm{D}]}$. Finally, the selectional $\mathrm{D}$-feature is checked by merging $\mathrm{vP}_{[\mathrm{S}: \mathrm{D}]}$ with the DP Mary. The external argument is added to this vP in the same manner as in (7).

Semantically, (7) and (8) yield the same results. We write $i^{*}{ }_{\mathrm{FOR}}$ to abbreviate the $i^{*}$ head with the root $\sqrt{ }$ FOR adjoined to it. We assume it has the semantics in (9), and the vP the semantics in (10). We write $\mathrm{vP}_{1}$ for the lower instance of $\mathrm{vP}$, and $\mathrm{vP}_{2}$ for the higher instance.

$$
\begin{aligned}
& \llbracket i *_{\mathrm{FOR}} \rrbracket=\lambda \mathrm{x} \lambda \mathrm{e} . \text { BENEFICIARY }(\mathrm{x}, \mathrm{e}) \\
& \llbracket \mathrm{vP}_{1} \rrbracket=\lambda \mathrm{e} . \text { hold }(\text { the purse }, \mathrm{e})
\end{aligned}
$$

Given this, when $i_{\text {FOR }}^{*}$ merges with the DP first, and then the vP, as in (7), the result is as in (11) (see Wood 2015: 22--26 for definitions of the compositional mechanisms invoked below):
a. $\llbracket \mathrm{pP} \rrbracket=\lambda$ e. BENEFICIARY(Mary,e)
(by Functional Application)
b. $\llbracket \mathrm{vP}_{2} \rrbracket=\lambda \mathrm{e}$. hold(the purse,e) \& BENEFICIARY(Mary,e)
(by Predicate Conjunction)

When $i_{\text {FOR }}$ merges with the vP first, and then the DP, as in (8), the result is as in (12).
a. $\llbracket \mathrm{vP}_{[\mathrm{S}: \mathrm{D}]} \rrbracket=\lambda \mathrm{x} \lambda \mathrm{e}$. hold(the purse,e) \& $\operatorname{BENEFICIARY}(\mathrm{x}, \mathrm{e})$
(by Event Identification)
b. $\llbracket \mathrm{vP}_{2} \rrbracket=\lambda$ e. hold(the purse,e) $\&$ BENEFICIARY(Mary,e)
(by Functional Application)

Both ways of combining $i^{*}$ FOR with a DP and a vP yield the same semantic representation, as can be seen in (11b) and (12b).

In sum, our proposal involves one argument introducing head, varying in terms of what it takes as a complement, and whether or not a root is adjoined to it. Now that we have introduced the basic layout of the system we propose, we turn to the empirical focus of the article, which provides support for the basic architecture we are defending, one where a relatively autonomous syntax is subject to specific interpretive rules at the interfaces with semantics and morphophonology, generating apparent mismatches between the first-merged positions of arguments and the syntactic loci that determine their thematic interpretation. The general picture will provide support for the view outlined here, that voice, little $\mathrm{p}$ and low appl are syntactically identical, semantically identical (in that their interpretation is conditioned by the semantics of the constituent they attach to), and different from $\mathrm{P}$ and high appl only in having no lexical root adjoined to them. 


\section{Voice and p: Icelandic figure reflexives}

In figure reflexives, a thematic "figure" role is introduced inside the $\mathrm{pP}$ complement of $\mathrm{v}$, and saturated by a DP in SpecvoiceP. The external argument in figure reflexives may also receive from the voice head an agent role in addition to the figure role.

$$
\text { [voice } B j a r t u r \quad \text { voice }[\mathrm{vP} \text { squeeze } \quad[\mathrm{pP} \text { FIGURE through the crowd }]]]
$$

An Icelandic figure reflexive is illustrated in (16), along with the bracketing to indicate its basic syntactic structure (sticking to labels like "voice" and "p" for the moment). ${ }^{5}$

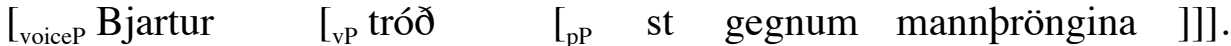

$$
\begin{aligned}
& \text { [voicep Bjartur.NOM [ [vP squeezed }\left[_{\mathrm{pP}}-\mathrm{ST}\right. \text { through the.crowd ]]] } \\
& \text { 'Bjartur squeezed through the crowd.' }
\end{aligned}
$$

The point of interest raised by the analysis of Icelandic figure reflexives stems from the following three considerations:

(i) Bjartur in (16) is interpreted as though it has two $\theta$-roles, "agent" and "figure", the latter role originating inside the $\mathrm{pP}$;

(ii) Bjartur is an external argument externally merged in SpecvoiceP (i.e. these are not unaccusative constructions);

(iii) There are no reflexive morphemes in the structure.

These claims are defended at length in Wood $(2014,2015)$, but we will provide a brief overview here. (i) can be appreciated by comparing (16) with the sentences in (17).
a. Bjartur tróð blýöntunum í pokann.
Bjartur.NOM squeezed the.pencils.DAT in the.bag
'Bjartur squeezed the pencils in the bag.'
b. Bjartur tróð sér gegnum mannpröngina. Bjartur.NOM squeezed REFL.DAT through the.crowd 'Bjartur squeezed himself through the crowd.'

In (17), Bjartur is no longer interpreted as the "figure", because there is another DP that bears this role: the pencils in (17a) and the reflexive pronoun in (17b). When the lower DP is gone, as in (16), Bjartur is understood as bearing the role that the lower DP bears in (17).

As for (ii), that Bjartur is externally merged in SpecvoiceP is shown by a number of considerations; for example, the sentence in (16) can be passivized, as illustrated in (18).
Рað var troðist
gegnum mannpröngina.
EXPL was squeezed-sT through the.crowd
'There was squeezing through the crowd.'

\footnotetext{
${ }^{5}$ The following abbreviations are used in this paper: $1=$ ' 1 st person', $3=$ ' 3 rd person', $\mathrm{ACC}=$ 'accusative', CAUS $=$ 'causative', DAT $=$ 'dative', $\mathrm{EXPL}=$ 'expletive', $\mathrm{GEN}=$ 'genitive', $\mathrm{NEG}=$ 'negative', $\mathrm{NOM}=$ 'nominative', $\mathrm{O}=$ 'object', $\mathrm{PAST}=$ 'past tense', $\mathrm{S}=$ 'subject', $\mathrm{ST}=$ 'Icelandic - st morphology', REFL = 'reflexive'.
} 
Impersonal passives in Icelandic diagnose the presence of an external argument interpreted as an agent (Sigurðsson 1989: 315-321, Thráinsson 2007: 266-269). This shows that Bjartur in (16) is externally merged in SpecvoiceP, and gets an agent role in addition to a figure role. ${ }^{6}$

Turning to (iii), unlike (17b), there is no reflexive morpheme in (16). The $-s t$ morpheme is not, by itself, reflexive, and there is no evidence that it may bear a $\theta$-role. The reflexive reading of some -st verbs is an old and interesting problem, but in general, "reflexive verbs" are expressed with separate reflexive pronouns. This even holds for "inherent" reflexive verbs (e.g. hegða sér vel 'behave oneself'), which can only take a reflexive object, and "natural reflexives" like raka sig 'shave oneself', which most naturally take a reflexive object. Note that these SEreflexives stand in opposition to complex, "self"-reflexives in the familiar way (see Sigurjónsdóttir 1992; Wood 2015: 41). The -st morpheme ultimately does contribute to the reflexive meaning of (16), but it cannot be maintained that -st can in any way bear a $\theta$-role or be "co-indexed" with a DP.

Wood $(2014,2015)$ proposes that $-s t$ is an argument expletive (Schäfer 2008, this volume; Sigurðsson 2012; Alexiadou et al. 2015): it merges in an argument position syntactically (before cliticizing to the verbal complex), but is effectively invisible in the semantics. The consequence of this "semantic invisibility" depends on which specific position -st occupies. For example, suppose it merges in the external argument position, as in (19b).
a. María opnaði hurðina. $\quad\left[{ }_{\mathrm{v} * \mathrm{P}}\right.$ Mary $i^{*}{ }_{\mathrm{v \textrm {P }}}$ opened the door $\left.]\right]$ Mary.NOM opened the.door.ACC 'Mary opened the door.'
b. Hurðin opnaðist.
door.the.NOM opened-ST
'The door opened.'

In (19a), the DP María merges as the external argument of open the door. In this case, $i^{*}$ may be interpreted as introducing an agent $\theta$-role, which will be saturated by (the denotation of) María. In (19b), -st merges in this same position, which satisfies the D-feature introduced by $i^{*}$. But in the semantics, since $-s t$ is basically invisible, the consequence is that $i^{*}$ may not introduce an external $\theta$-role. The result is an anticausative interpretation: a door-opening event is asserted, but no external cause or agent is expressed (see Schäfer this volume). (We elaborate on the interpretation of the causative/inchoative-alternation in section 4.2 below.)

There are, then, at least two allosemes - contextually conditioned interpretations - of $i^{*}$, as illustrated in (20). (Double arrows indicate an interpretation inserted into a terminal node postsyntactically; equal signs indicate a denotation computed on a nonterminal node by some compositional mechanism.)

\footnotetext{
${ }^{6}$ A reviewer points out that impersonal passivization isn't a good diagnostic for external-argumenthood/agency in Dutch, citing Den Dikken (2010: 50-51). As far as has been determined, the diagnostic does hold for Icelandic; see Sigurðsson (1989: 315-321) for extensive discussion of the agency effect, and Thráinsson (2007: 266-269) for a review of the relevant facts. Note that if Maling and Sigurjónsdóttir (2002) are correct, impersonal passives might for some speakers actually be impersonal active constructions. Crucially, however, figure reflexives are passivizeable for all speakers. See Wood (2015: 179ff.) for a battery of further tests pointing to the conclusion that figure reflexives are agentive. Thus, even if Icelandic turned out to be like Dutch in that impersonal passivization doesn't unambiguously diagnose agentivity, there is independent evidence that the subject of figure reflexives is agentive.
} 

a. $\llbracket i * \rrbracket \leftrightarrow \lambda \mathrm{x} \lambda \mathrm{e}$. $\operatorname{AGENT}(\mathrm{x}, \mathrm{e}) / \_$(agentive vP)
b. $\llbracket i * \rrbracket \leftrightarrow \lambda \mathrm{x} . \mathrm{x}$

(20a) introduces an agent role, while (20b) is "expletive" voice: it simply takes the denotation of its complement $\mathrm{vP}$ and returns that same denotation. (We show below that the availability of an expletive interpretation is a general option for, and perhaps even a defining property of, bare $i^{*}$.) The choice between (20a) and (20b) is made in the semantics, after syntactic structure is built and sent to spellout. If the vP is interpreted as the sort of event that has an agent, (20a) is chosen. If the vP is interpreted as the sort of event that happens on its own (see Haspelmath 1993; Schäfer 2008; Alexiadou et al. 2015: ch3), (20b) is chosen. An event like "open the door" can be construed in either way, so both the allosemes in (20a) and (20b) are available. Other events, such as events built with verbs like 'murder', must be construed agentively, so only (20a) will be available. Still other events, such as those built with verbs like 'blossom', must be construed as happening on their own, so only (20b) will be available.

Importantly, certain structures are only compatible with one alloseme or another. For example, when there is a DP external argument, (20b) is impossible unless there is some other mechanism for integrating that DP semantically into the interpretation of the vP (see Wood 2015: 143ff., and section 4 below). Similarly, when an expletive element such as Icelandic -st is in the external-argument position, (20a) is impossible unless there is some other mechanism for semantically saturating the agent role (see Wood 2015: 259ff.). Thus, if we choose an event that requires (20a), but try to put -st in the external-argument position, the result is ungrammatical:

$$
\begin{aligned}
& \text { * Maðurinn myrtist. } \left.\left.{ }_{\mathrm{v} * \mathrm{P}}-\text { st } i *{ }_{\mathrm{vP}} \text { murdered the man }\right]\right] \\
& \text { the.man.NOM murdered-ST } \\
& \text { INTENDED } \approx \text { 'There was an event of murdering the man.' }
\end{aligned}
$$

The reason that $i^{*}$ cannot introduce an external $\theta$-role is that doing so would violate "Full Interpretation" (Harley 2011); the external $\theta$-role wouldn't be saturated, because when $i *$ attaches to vP, it is the highest argument-introducing head, closing off the vP domain; once -st takes that position, there are no more arguments to saturate that $\theta$-role. When -st merges in the "figure" position, which is SpecpP according to Svenonius $(2003,2007)$, this is not the case. Merging $i^{*}$ with a PP only closes off the PP-domain, but there are more positions in the dominating vP in which an argument can be introduced. Therefore, the "figure" role can be introduced semantically as the external argument of the PP, but saturated by a DP introduced higher in the structure. This is schematically illustrated in the tree in (22), whose compositional semantics is given in (a)-(j). 
(22)

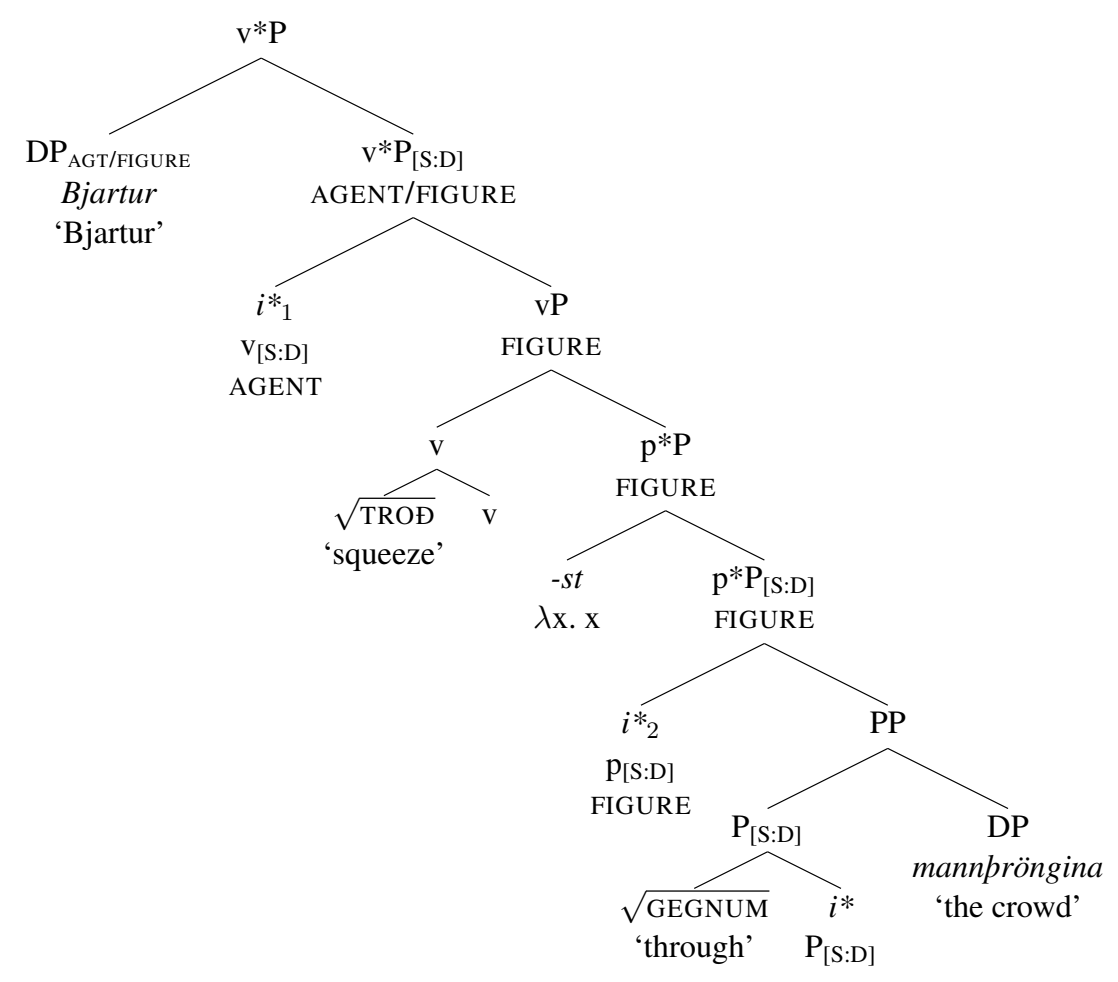

a. $\llbracket \mathrm{PP} \rrbracket=\lambda \mathrm{s}$. through $($ the crowd,s)

b. $\llbracket i *_{2} \rrbracket \leftrightarrow \lambda \mathrm{x} \lambda \mathrm{s}$. $\operatorname{FIGURE}(\mathrm{x}, \mathrm{s})$

c. $\llbracket \mathrm{p}^{*} \mathrm{P}_{[\mathrm{S}: \mathrm{D}]} \rrbracket=\lambda \mathrm{x} \lambda \mathrm{s}$. $\operatorname{FIGURE}(\mathrm{x}, \mathrm{s}) \&$ through(the crowd,s)

(c) comes from (a) and (b) by Event Identification

d. $\llbracket-s t \rrbracket=\lambda \mathrm{x} . \mathrm{x}$

e. $\llbracket \mathrm{p} * \mathrm{P} \rrbracket=\lambda \mathrm{x} \lambda \mathrm{s}$. $\operatorname{FIGURE}(\mathrm{x}, \mathrm{s}) \& \operatorname{through}($ the crowd,s)

(e) comes from (c) and (d) by Functional Application

f. $\quad \llbracket \mathrm{v} \rrbracket \leftrightarrow \lambda \mathrm{P}_{<\mathrm{s}, \mathrm{t}} \lambda \mathrm{e} \exists \mathrm{s} . \mathrm{P}(\mathrm{s}) \&$ squeeze(e) \& $\operatorname{CAUSE}(\mathrm{e}, \mathrm{s})$

g. $\llbracket \mathrm{vP} \rrbracket=\lambda \mathrm{x} \lambda \mathrm{e} \exists \mathrm{s}$. $\operatorname{FIGURE}(\mathrm{x}, \mathrm{s}) \& \operatorname{through}($ the crowd,s) \& squeeze(e) \& CAUSE(e,s)

$\approx$ 'The set of squeezing events which cause $\mathrm{x}$ to go through the crowd' (g) comes from (e) and (f) by Function Composition

h. $\llbracket i *_{1} \rrbracket \leftrightarrow \lambda \mathrm{x} \lambda \mathrm{e}$. $\operatorname{AGENT}(\mathrm{x}, \mathrm{e})$

i. $\llbracket \mathrm{v}^{*} \mathrm{P}_{[\mathrm{S}: \mathrm{D}]} \rrbracket=\lambda \mathrm{x} \lambda \mathrm{e} \exists \mathrm{s} . \operatorname{AGENT}(\mathrm{x}, \mathrm{e}) \& \operatorname{FIGURE}(\mathrm{x}, \mathrm{s}) \&$ through(the crowd,s) \& squeeze(e) \& CAUSE(e,s)

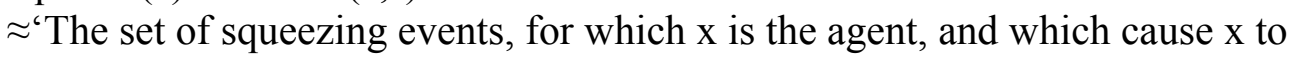
go through the crowd.'

(i) comes from (g) and (h) by Predicate Conjunction

j. $\quad \llbracket \mathrm{v}^{*} \mathrm{P} \rrbracket=\lambda \mathrm{e} \exists \mathrm{s}$. AGENT(Bjartur,e) \& FIGURE(Bjartur,s) \& through(the crowd,s) $\&$ squeeze(e) \& CAUSE(e,s)

$\approx$ 'The set of squeezing events, for which Bjartur is the agent, and which cause Bjartur to go through the crowd.' 
In plain language, what happens in the interpretation of the tree in (22) is this. The lower $i^{*}{ }_{2}$ head introduces a figure role. (Subscripts are for presentational purposes only.) Since -st merges in the argument position $i^{*}$ makes available, however, that role is not saturated within the p*P. Semantic composition proceeds, leaving that role unsaturated, until the higher $i^{*}$ introduces an agent role. It combines in such a way that the two unsaturated roles are identified with one another, so that whatever merges as the external argument will be the semantic argument of both the agent relation and the figure relation. This is how a reflexive-like interpretation is achieved without any anaphoric element in the structure. (See Schäfer this volume for an Agree-based computation of true reflexives.)

We are now in a position to compare the structural properties of voice, which we have proposed is $i^{*}$ attaching to $\mathrm{vP}$, and Svenonius's $(2003,2007)$ little $\mathrm{p}$, which we have proposed is $i^{*}$ attaching to $\mathrm{pP}$. Both voice and $\mathrm{p}$ introduce an external-argument DP related to their complement. Neither imposes any special case or c-selectional restrictions on its specifier (other than the fact that it is of category D). Both allow -st in Icelandic to merge instead of a DP; while the semantic consequences of -st are different in each case, these differences are derivable entirely from the positions -st occupies. Finally, both are interpreted semantically as introducing a role already implied by the semantics of their complements: voice introduces an agent role if its vP complement denotes the sort of event that implies an agent, and $p$ introduces a figure role if its PP complement denotes the sort of spatial state that implies a figure. All of this follows if we assume that voice and $\mathrm{p}$ are, in terms of their syntactic features, one and the same head-which we are calling $i^{*}$. The rules for interpreting $i^{*}$ discussed so far are shown in (23). ${ }^{7}$
a. $\llbracket i * \rrbracket \leftrightarrow \lambda \mathrm{x} \lambda \mathrm{s}$. $\operatorname{FIGURE}(\mathrm{x}, \mathrm{s}) /$ (locative $\mathrm{pP}$ )
b. $\llbracket i * \rrbracket \leftrightarrow \lambda \mathrm{x} \lambda \mathrm{e}$. $\operatorname{AGENT}(\mathrm{x}, \mathrm{e}) /$ (agentive vP)
c. $\llbracket i * \rrbracket \leftrightarrow \lambda \mathrm{x} . \mathrm{x}$

Before closing this section, we briefly address a question raised by two reviewers, which is whether there is any connection between Icelandic -st figure reflexives and the wayconstruction (Jackendoff 1992; Marantz 1992; Mateu 2005). As noted in Wood (2015: 193) and illustrated in (24), Icelandic also has a way-construction, where the possessor is expressed as a dative reflexive rather than a DP-internal possessive pronoun.

Risarotta nagaði sér leið inn á heimili í Stokkhólmi. giant.rat gnawed REFL.DAT way in to home in Stockholm 'A giant rat gnawed its way into a home in Stockholm.'

In fact, there are important differences between figure reflexives and way-constructions. For example, it would be possible (though perhaps marked) to form a way-construction from a verb like 'murder', as shown in (25a), but it is impossible to form a figure reflexive with 'murder', as shown in (25b). (Icelandic data comes from Einar Freyr Sigurðsson, p.c.)

a. (?)Hann myrti sér leið til valda.
he murdered REFL.DAT way to power
'He murdered his way to power.'

\footnotetext{
${ }^{7}$ See Wood (2015: 197-204) for constructions where $i^{*}$ has the interpretation in (23c) when it merges with a PP.
} 


\section{b. *Hann myrtist til valda. he murdered-ST to power INTENDED:*'He murdered to power.'}

The crucial difference is that way-constructions require activity verbs (or verbs coerced into an activity meaning); their meaning is constructed by adding a small clause to this activity verb interpretation. The semantics of figure reflexive constructions combines an activity with a semantically unsaturated path predicate, which forces the verb to be interpreted as a verb of motion. (Note that figure reflexives have no direct object that can be used to 'measure out' an activity event.) That is, in order for (25b) to be acceptable, it would have to be possible to interpret 'murder' as a verb of motion. In (25a), 'murder' is interpreted as an activity that creates the path expressed in the small clause, but it is not part of the traversal of the path.

To summarize, we have proposed that there is one head, $i^{*}$, that introduces the external arguments of vPs and pPs. Its syntactic properties are derived from its structural environment: it projects the syntactic category of its complement, it assigns the thematic role implied by its complement, it can be expletive, and the range of interpretations available to it are constrained only by "Full Interpretation".

\section{Possessor Raising in Change-of-State vPs}

In this section, we extend the system discussed in the previous two sections to Japanese adversity causatives. To do this, we first show how our system generates several other kinds of thematic dependencies, including clausal possession, change-of-state vPs, and possessor-raising constructions, which, when combined, will derive the properties of Japanese adversity causatives.

\subsection{Clausal possession, low and high}

Myler (2014) demonstrates that clausal possession in Quechua can take several different forms. The form relevant to this discussion is what Myler calls the "BE-APPL" construction in Cochabamba Quechua. It is exemplified in (26).

(26) Noqa-qta auto tiya-pu-wa-n.

I-GEN car be EXIST $^{-A P P L-10-3 S}$

'I have a car.'

Myler argues that in (26), the possession relation is introduced internal to the possessed DP, but is saturated semantically by a DP introduced syntactically in the specifier of an appl head. Abstracting away from some details (Myler's PredP in particular), the basic structure Myler proposes for (26) is (27).

$$
\left[\text { ApplP } \text { SPEAKER appl }\left[_{\mathrm{vP}} \mathrm{v}_{\mathrm{EXIST}}\left[{ }_{\mathrm{DP}} \mathrm{D}\left[{ }_{\mathrm{PossP}} \text { poss }\left[_{\mathrm{nP}} \text { car }\right]\right]\right]\right]\right]
$$

Semantically, Poss introduces a possession relation, which remains unsaturated within its DP, much as the figure of figure reflexives remains unsaturated within the $\mathrm{pP}$. The existential copula is argued to be semantically expletive, as is the appl head that ultimately introduces the possessor DP.

Importing this analysis into the current proposal, we can ask what kinds of heads Myler's appl and poss are. As for poss, it is quite possible that it is another use of bare $i^{*}$. Semantically, 
the possession relation would be the interpretation of $i^{*}$ when it takes an $\mathrm{nP}$ complement. ${ }^{8}$ As for Myler's appl, it is fairly clear that this is also an unmodified $i^{*}$; it is interpreted expletively (and thus adds no thematic content to the structure on its own), so it falls into the class of heads like voice, low appl and little $\mathrm{p}$ (rather than canonical high appl or big P). Given the structure that Myler proposes, with appl taking a vP complement, the most immediately natural interpretation is that it is a kind of voice head. However, given that the existential copula makes no direct semantic contribution, it is also possible that appl $\left(=i^{*}\right)$ merges below $\mathrm{v}$, and is thus more like a low appl head. We will adopt the latter option for expository purposes, and propose the modified structure of (27) in (28).

$$
\left[{ }_{\mathrm{vP}} \mathrm{V}_{\text {EXIST }}\left[\mathrm{DP} \text { SPEAKER } i^{*}\left[{ }_{\mathrm{DP}} \mathrm{D}\left[{ }_{\mathrm{nP}} i^{*}\left[{ }_{\mathrm{nP}} \text { car }\right]\right]\right]\right]\right]
$$

Even if (28) is the correct analysis of the Quechua BE-APPL construction, the other interpretation of (27) in the current proposal is nevertheless attested. Myler proposes that English sentences like John has a car have the structure in (29a), which according to our proposal would be (29b). ${ }^{9}$
a. [ [voicep John voice $\left[_{\mathrm{vP}} \mathrm{V}\left[{ }_{\mathrm{DP}} \mathrm{D}\left[{ }_{\mathrm{poss}}\right.\right.\right.$ poss $\left.\left.\left.\left.\left[{ }_{\mathrm{nP}} \mathrm{car}\right]\right]\right]\right]\right]$
b. $\left[{ }_{\mathrm{v} * \mathrm{P}}\right.$ John $i^{*}\left[{ }_{\mathrm{vP}} \mathrm{V}\left[{ }_{\mathrm{DP}} \mathrm{D}\left[{ }_{\mathrm{nP}} i^{*}\left[{ }_{\mathrm{nP}}\right.\right.\right.\right.$ car $\left.\left.\left.\left.]\right]\right]\right]\right]$

Recall that earlier, we argued that prepositions can either merge with a DP and then a vP (yielding what looks like a standard vP-adjunct $\mathrm{pP}$ ) or with a vP and then a DP (yielding what looks like a canonical high appl), with no difference in the thematic semantics entailed. If Myler's proposal is correct, we have another example of structures where the same syntactic elements can merge in a different order and yield the same semantic results. Clausal possession is built when a DP introduces a possession relation that is not saturated DP-internally. The elements needed to do so are a verbalizing $\mathrm{v}$ head and an (or rather, the) argument-introducing head, $i^{*}$. Either $i^{*}$ merges first (introducing the possessor), followed by the $\mathrm{v}$ head, or else the $\mathrm{v}$ head merges first, followed by $i *$ (introducing the possessor). We will see that these same analytical options present themselves in the distinction between possessor raising and adversity causatives. First, however, we must present our analysis of change-of-state vPs.

\subsection{Change-of-state vPs}

Marantz (2009a,b, 2013) has argued that the basic structure of a change-of-state vP involves only one $\mathrm{v}$ head, which takes a DP complement. The way change-of-state semantics are computed from this configuration is as follows. First, there is a general coercion rule such that the internal argument of a change-of-state is interpreted as a result state. This is illustrated in (30).

$$
\llbracket \mathrm{DP} \rrbracket \rightarrow \operatorname{sTATE}(\llbracket \mathrm{DP} \rrbracket)=(\lambda \mathrm{x} \lambda \mathrm{s} . \operatorname{state}(\mathrm{s}, \mathrm{x}))(\llbracket \mathrm{DP} \rrbracket)
$$

For both a causative sentence like John shattered the window, and an inchoative sentence like The window shattered, the interpretation of the DP internal argument would ultimately be as in (31).

\footnotetext{
${ }^{8}$ We abstract away from how the D-feature of $i^{*}$ is ultimately checked in this configuration. See Myler 2014 and Wood 2015 for some options. A possibility in addition to those discussed there is that the fact that the D-head merges anyway, to form the DP, is enough to check the D-feature.

${ }^{9}$ For an extended defense of this structure, and arguments against preposition-incorporation approaches to the relation between HAVE and BE, see Myler 2014 chapters 2 and 4.
} 
What happens next depends on the structure. In an inchoative structure, with no external argument, the interpretation of $\mathrm{v}$ will introduce inchoative semantics of the sort often abbreviated as BECOME.

$$
\llbracket \mathrm{v} \rrbracket \leftrightarrow \lambda \mathrm{P}_{<\mathrm{s}, \mathrm{t}} \lambda \mathrm{e} \exists \mathrm{s} . \operatorname{BECOME}(\mathrm{s}, \mathrm{e}) \& \mathrm{P}(\mathrm{s}) / \ldots \text { (no external argument) }
$$

That is, $v$ denotes the event of the result state coming to hold. If, however, there is an external argument, the interpretation of $\mathrm{v}$ can introduce a causing event, as illustrated in (33). (We will see in section 4.4, as we saw in section 4.1 , that there are also instances where there is an external argument but $\mathrm{v}$ is interpreted as an expletive.)

$$
\llbracket \mathrm{v} \rrbracket \leftrightarrow \lambda \mathrm{P}_{<\mathrm{s}, \mathrm{t}>} \lambda \mathrm{e} \exists \mathrm{e}^{\prime} . \mathrm{P}\left(\mathrm{e}^{\prime}\right) \& \operatorname{CAUSE}\left(\mathrm{e}^{\prime}, \mathrm{e}\right) / \ldots \text { (external argument) }
$$

What is syntactically represented in a causative, then, is the causing event, introduced by $\mathrm{v}$, and the result state, introduced by the coercion rule in (30) applied to the DP object. What is not syntactically represented is the "become" part of the change-of-state event. The change-of-state is syntactically represented in the juxtaposition of $\mathrm{v}$ and the DP object. That is, the $\mathrm{v}$ presents an event variable and the causing event and the DP creates the stative "event," with the "change" meaning coming in as the interpretation of the relation between the events. What is available for adverbial modification ("John opened the door quickly") and presupposition via re-prefixation ("John re-opened the door" presupposes "the door was open before") are the "e' CAUSEs e, [change of] state s" and the "state s" from (32) and (33) - two things and no more. The changeof-state is not separately available. Note that this analysis of the relationship between (lexical) causatives and inchoatives built on the same root explicitly denies that either is built from the other structurally or derivationally; the main event in the inchoative, asserted via $v$, is "become," while "become" finds no explicit syntactic representation in the causative.

We can notate this analysis of the source of change-of-state semantics within causatives as a semantic combinatory rule in the notational style of Heim and Kratzer (1998) as in (34).

(34) If $\alpha$ is a branching node, and $\{\mathrm{v}, \mathrm{DP}\}$ the set of $\alpha$ 's daughters, then $\llbracket \alpha \rrbracket=\llbracket \mathrm{v} \rrbracket\left(\left(\lambda \mathrm{P}_{<\mathrm{s}, \mathrm{t}} \lambda \mathrm{e} \exists \mathrm{s}\right.\right.$. BECOME$\left.\left.(\mathrm{s}, \mathrm{e}) \& \mathrm{P}(\mathrm{s})\right)(\llbracket \mathrm{DP} \rrbracket)\right)$.

That is, v+DP is interpreted by taking the interpretation of the DP (result state), applying it to the "become" predicate, and feeding that to the interpretation of v. Since the "become" predicate cannot be tied to any specific syntactic node, but results instead from a special combinatory rule, it cannot be modified by adverbs like quickly or again, singled out for presupposition by reprefixation, or targeted for clausal negation. Note that this rule must be understood to apply only to the eventive- $\mathrm{v}$ that coerces the change of state interpretation of the DP complement, and not to the stative-v involved in deriving clausal possession. As Myler (2014) argues, the latter is pronounced as have in English, while the former is pronounced as get (see Wood and E.F. Sigurðsson 2014). Since the difference in pronunciation correlates with a difference in interpretation, the distinction between stative- and eventive-v must be rooted somewhere in the 
syntax, but we will not develop an account of what that difference is here (see Alexiadou et al. 2015 for the same conclusion).

\subsection{Possessor-raising}

Possessor-raising constructions such as (35) seem to combine properties of the analyses in the previous two subsections.

Ha-yalda kilkela le-Dan et ha-radio.

the-girl spoiled to-Dan ACC the-radio

'The girl broke Dan's radio on him.'

(Pykkänen 2008: 46, citing Landau 1999)

On the one hand, they involve an external possessor in what looks like a low applicative position saturating a possessor relation determined DP-internally. (See Pykkänen 2008 on the low applicative analysis.) On the other hand, they involve change-of-state semantics on the internal argument. Given the analyses in the previous two subsections, the syntax creates two kinds of interpretive demands on the structure. In order for the possessor relation to be saturated by the external DP, the possessor relation must remain unsaturated. And yet, in order for the change-of-state semantics to be computed, the DP has to be interpreted as a result state. This is illustrated schematically in (36).

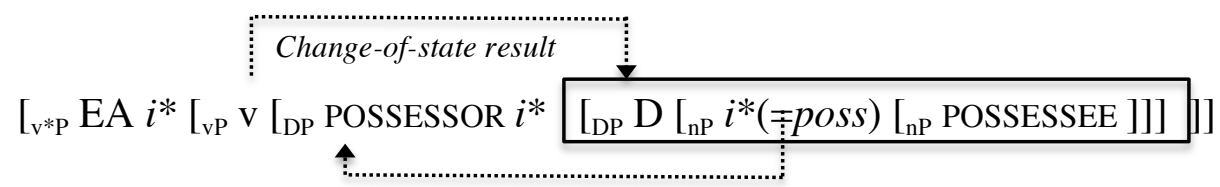

Notice, however, that this result can be achieved by combining the analysis of change-ofstate vPs with the analysis of figure reflexives. For change-of-state semantics, we have a coercion rule as in (37).

$$
\llbracket \mathrm{DP} \rrbracket \rightarrow \operatorname{sTATE}(\llbracket \mathrm{DP} \rrbracket)=(\lambda \times \lambda \mathrm{s} . \operatorname{state}(\mathrm{s}, \mathrm{x}))(\llbracket \mathrm{DP} \rrbracket)
$$

Given the denotation of a DP with an unsaturated possessor relation, we have composition as in (38), where (38b) derives from (38a) by function composition.
a. $(\lambda x \lambda$ s. state $(\mathrm{s}, \mathrm{x}))(\lambda \mathrm{y} .1 \mathrm{x} . \operatorname{POSS}(\mathrm{x}, \mathrm{y}))$
b. $\lambda y \lambda s . \operatorname{state}(s, 1 x . P O S S(x, y))$

Given the denotation in (38b), low appl will be interpreted as expletive, and the argument it introduces will saturate the possession relation. All other semantic processes outlined in the previous subsection apply in exactly the same way.

Note that possessor-raising constructions of this sort tend to have, in addition to the purely thematic possessive reading, a kind of "affectedness" reading. The translation of (35), for example, is not just 'The girl broke Dan's radio,' but 'The girl broke Dan's radio on him.' We don't have much to say about this affectedness reading, which is also found in the Japanese adversity causatives discussed in the next subsection, except to note that such affected roles are strictly speaking distinct from the tier of thematic interpretive roles like beneficiary, possessor, 
agent, etc. Bosse et al. (2012) argue that this kind of meaning is projected on a non-truthconditional semantic tier, which operates in parallel to, but is strictly distinct from, the truthconditional tier (see also Horn 2013). In particular, unlike arguments, including standard applicative arguments, these affected arguments stand outside the scope of negation. Here, we focus on the aspects of meaning that are projected on the truth-conditional tier and provide no new account of the source of affected readings (see Bosse et al. for further discussion).

\subsection{Japanese adversity causatives}

Japanese adversity causatives are formally similar to Icelandic figure reflexives in that the interpretation of an external argument depends on the properties of the internal argument. In particular, a thematic "possessor" role is introduced inside the DP complement of $\mathrm{v}$, and saturated by a DP in SpecvoiceP.

$$
\text { [ }{ }_{\text {voicep }} \text { Taroo voice }\left[{ }_{\mathrm{vP}}\right. \text { die-CAUSE [DP POSSESSOR son ]]] }
$$

An adversity causative is illustrated in (40), along with the bracketing to indicate its syntactic structure.

$$
\begin{array}{lll}
{\left[{ }_{\text {voiceP }}\right. \text { Taroo-ga }} & { }_{\mathrm{vP}}\left[{ }_{\mathrm{DP}} \text { musuko-o }\right] & \text { sin-ase }]]-\mathrm{ta} . \\
{\left[_{\text {voiceP }}\right. \text { Taroo-NOM }} & {\left[{ }_{\mathrm{vP}}\left[{ }_{\mathrm{DP}} \text { son-ACC }\right]\right.} & \text { die-CAUS }]]-\mathrm{PAST}
\end{array}
$$

(i) 'Taro caused his son to die.'

(ii) 'Taro's son died on him.'

Japanese adversity causatives have a few notable properties (Oehrle and Nishio 1981; Miyagawa 1989; Pylkkänen 2008). First, they seem to look, morphosyntactically, like plain transitive lexical causatives, and as indicated in the first translation of (40), they may be interpreted as such. Second, the adversity reading is only possible when the "affectee" subject is understood as the possessor of the internal argument. Third, adversity causatives are generally only possible on transitive structures for which there also exists an intransitive, unaccusative counterpart. Consistent with this last generalization, adversity causatives are morphophonologically identical to lexical causatives, built directly on a verbal root, and not to syntactic causatives in the many cases where these are morphophonologically distinguishable (e.g., when the syntactic causative is built on top of a lexical causative; see Harley this volume for discussion of such cases).

The analysis of the adversity causatives that we propose builds on the analysis of possessor raising outlined in the previous subsection, combined with the analysis of clausal possession of the English sort outlined in section 4.1. Recall that there, we saw that clausal possession can be derived in at least two ways from a DP with an unsaturated possessor relation. First, $i^{*}$ and the possessor can combine with the DP possessee first, with the result then combining with v. This was our adaptation of Myler's proposal for Quechua BE-APPL constructions. Second, v can combine with the DP possessee first, followed by $i^{*}$ and the possessor; this was the analysis of English clausal possession with have.

The analysis of possessor raising given in the previous subsection was essentially the first option, combined with a change-of-state predicate. The analysis of Japanese adversity causatives is essentially the second option, combined with a change-of-state predicate. Adversity causatives look like plain transitive causatives because they have the same syntactic structure as plain tran- 
sitive causatives, shown in (41). (See Schäfer this volume on the dissociation of syntactic and semantic transitivity.)

$$
\left[{ }_{\mathrm{v} * \mathrm{P}} \operatorname{EXT}-\mathrm{ARG} i *\left[{ }_{\mathrm{vP}} \mathrm{v} \text { DP }\right]\right]
$$

Recall that earlier, we argued that the interpretation of $i^{*}$ in the context of a vP depends on the semantics of that vP. For a change-of-state event that can happen without an agent, $i^{*}$ may be interpreted as expletive. We also noted, however, that when there is an external argument present, $i^{*}$ cannot be interpreted as expletive unless there is some other way to integrate the external argument into the semantics of the vP. If the internal argument DP introduces a possessor role which remains unsaturated within that DP, the external argument can be integrated into the semantics of the vP by saturating that possessor role. This is illustrated in (42).
a. $\llbracket \mathrm{DP} \rrbracket=\lambda \mathrm{y} \lambda \mathrm{s} . \operatorname{state}(\mathrm{s}, \mathrm{x} \cdot \mathrm{POSS}(\mathrm{x}, \mathrm{y}) \& \operatorname{son}(\mathrm{x}))$
b. $\llbracket v \rrbracket \leftrightarrow \lambda x . x$
c. $\llbracket \mathrm{vP} \rrbracket=\llbracket \mathrm{v} \rrbracket\left(\left(\lambda \mathrm{P}_{<\mathrm{s}, \mathrm{t}} \lambda \mathrm{e} \exists \mathrm{s} . \operatorname{BECOME}(\mathrm{s}, \mathrm{e}) \& \mathrm{P}(\mathrm{s})\right)(\llbracket \mathrm{DP} \rrbracket)\right)$.
(by combinatory rule (32))
$\rightarrow \llbracket \mathrm{v} \rrbracket(\lambda \mathrm{y} \lambda \mathrm{e} \exists \mathrm{s} . \operatorname{BECOME}(\mathrm{s}, \mathrm{e}) \& \operatorname{state}(\mathrm{s}, \mathrm{x} \cdot \operatorname{POSS}(\mathrm{x}, \mathrm{y}) \& \operatorname{son}(\mathrm{x})))$
(by Function Composition)
$\rightarrow \lambda \mathrm{y} \lambda \mathrm{e} \exists \mathrm{s} . \operatorname{BECOME}(\mathrm{s}, \mathrm{e}) \& \operatorname{state}(\mathrm{s}, \mathrm{x} . \operatorname{POSS}(\mathrm{x}, \mathrm{y}) \& \operatorname{son}(\mathrm{x}))$
(by Functional Application)
d. $\llbracket i * \rrbracket \leftrightarrow \lambda \mathrm{x} . \mathrm{x}$
e. $\llbracket \mathrm{v}^{*} \mathrm{P} \rrbracket=\lambda \mathrm{e} \exists \mathrm{s} . \operatorname{BECOME}(\mathrm{s}, \mathrm{e}) \& \operatorname{state}(\mathrm{s}, \mathrm{x} . \operatorname{POSS}(\mathrm{x}, \mathrm{Taroo}) \& \operatorname{son}(\mathrm{x}))$
$\approx$ 'The set of events of Taroo's son coming to be in state s'10

Consider how this analysis captures the properties of adversity causatives mentioned at the beginning of this section. First, they look, morphosyntactically, like plain transitive causatives, because they have the same syntactic structure as plain transitive causatives. In particular, the allomorph of $\mathrm{v}$ chosen in a transitive environment for a particular root will be the same in the plain lexical causative and in the adversity causative. Second, the adversity reading is only available when the subject is the possessor because it is the possessor role that allows the subject to be integrated into the semantics of the vP in the first place. Without the possessor role, $i^{*}$ would have to introduce some other role (such as agent) in order for the DP external argument to be integrated into the semantic interpretation. Third, adversity causatives are only possible on transitive structures for which there also exists an unaccusative counterpart because it is precisely those structures that allow for the expletive alloseme of $i *$ in the context of a vP.

Note that according to this analysis, the causative morpheme in the Japanese adversity causative does not indicate causative semantics. The affix that we generally call the causative morpheme is simply the way that $\mathrm{v}$ is pronounced when there is a syntactic external argument (though see Harley this volume for some potentially challenging cases). In many cases, the presence of an external argument correlates with a causative interpretation of $\mathrm{v}$. In the Japanese adversity causative, however, no causing event is asserted. Thus, when a sentence like (40) is negated, as in (43), only three out of four imaginable interpretations are actually available. ${ }^{11}$

\footnotetext{
${ }^{10}$ Note that the verbal root will typically name the end state, which in a sentence like (40) will be the state of being dead; we omit this conjunct from the derivation in (42).

${ }^{11}$ Thanks to Yohei Oseki for discussion of the Japanese facts and judgments of the data.
} 
Taroo-ga musuko-o sin-ase-nakat-ta.

Taro-NOM son-ACC die-CAUS-NEG-PAST

(i) a. 'Taro's son died, but Taro didn't kill him.'

(negation of causing event)

b. 'Taro's son didn't die at all.'

(ii) a. *'Taro's son died, but without any cause.'

(negation of result)

b. 'Taro's son didn't die at all.'

(*negation of causing event)

(negation of result)

In the ordinary causative interpretation, given in (43i), clausal negation can negate either the causing event or the result. That is, the ordinary causative interpretation under negation is compatible with the son dying, but not by the asserted cause. In the adversity causative interpretation, on the other hand, only the result can be negated, although the adversity implication remains. (Taro's son dying would have resulted in adversity for Taro.) It isn't possible in the presence of negation to negate a cause of the change-of-state while retaining the assertion of the change-ofstate (and the adversity implication: nothing caused his son to die on Taro, although he did). These facts support our claim that causative semantics are not present in the adversity causative, despite the presence of causative morphology. The "causative" morphology does not reflect semantics, but rather the presence of $\mathrm{v}$ in a particular syntactic structure.

This analysis of the Japanese adversity causative agrees with Pylkkänen's (2008) in denying that the construction is built on the semantics of the inchoative form of the base verb and in providing an essentially transitive syntactic structure to the construction. The strongest evidence contrasting the inchoative (e.g., "Taro's son died") with the change-of-state semantics within the adversity causative is the impossibility of modifying the change-of-state with adverbials that can occur with the inchoative (e.g., "from natural causes," or "by itself"). Our analysis disagrees with Pylkkänen's in three crucial respects. First, as explained above, the present analysis denies that the adversity causative asserts causative semantics; some evidence for this conclusion is the failure of negation to deny causation, which is possible for negation with the lexical causative. Second, Pylkkänen analyzes the affected argument as an applicative argument; however, according to the distinctions motivated in Bosse et al. (2012), the affected role is not that of an applicative argument, being unable to scope under negation. Finally, Pylkkänen (2008) builds the adversity causative on top of the adversity passive, which she analyzes as an applicative construction; however, the adversity passive is a "high" construction, which can embed a syntactic causative, while the adversity causative is a "low" construction, necessarily built on the verbal rootthe causative thus couldn't be built on top of the passive.

What distinguishes between Japanese and English, preventing English from having the "adversity" causative reading of transitive verb phrases, is (i) the availability of the possessor raising structure, which allows a possessor role introduced inside a DP to be saturated externally to that DP in non-stative contexts, and (ii) the possibility for active voice above v not to assign the "agent" role, if another role is available. In fact, English does have adversity causatives when it can, exceptionally, do possessor raising, as in sentences like John broke an arm, which can mean that John is the adversely affected (inalienable) possessor of the arm that broke. Like in Japanese, John didn't break an arm, under the adversity causative reading, entails that John's arm wasn't broken, whereas John didn't break the window is perfectly compatible with the window breaking in some other way. 


\section{Conclusion}

In this chapter, we proposed an understanding of the syntax and semantics of external arguments that depends on an autonomous syntax, where the atoms of representations don't carry inherent semantic values. We first proposed a restricted system of argument introduction, where a single argument-introducing head varies only in terms of the syntactic context it is merged in. The relevant syntactic factors for eventual semantic interpretation include the category of its complement along with whether or not a lexical root adjoins to it. Semantically, this argument-introducing head generally assigns to the second constituent it merges with the $\theta$-role implied by the first constituent it merges with. After introducing the properties of the argument-introducing head, we applied the resulting system to a set of cases where the interpretation of an external argument depends on a $\theta$-role introduced somewhere lower in the structure. Icelandic figure reflexives involve an external argument that bears a figure role introduced inside a lower pP; clausal possession involves an external or applied argument bearing a possessor role introduced inside a lower DP; and adversity causatives and possessor raising involve, essentially, the analysis of clausal possession superimposed over change-of-state vP semantics. The basic system ends up being both restrictive and flexible. The restrictiveness stems from the fact that all argumentintroducing heads reduce to one syntactic head; any and all syntactic, morphological, and interpretive differences between prima facie distinct heads must be reduced to properties of the structure they occur in. We retain a tight connection between syntactic structure and thematic interpretation, because the latter is derived by interpretive rules defined on the former. And yet, the system is flexible, in that there is no particular principle forcing a DP with a particular thematic interpretation to occur in a particular syntactic position. All that is required is that semantic composition leads to a well-formed semantic representation. 


\section{References}

Acedo-Matellán, Víctor. 2010. Argument Structure and the Syntax-Morphology Interface: A Case Study in Latin and Other Languages: Universitat de Barcelona Doctoral Dissertation.

Alexiadou, Artemis, Elena Anagnostopoulou and Florian Schäfer. 2015. External Arguments in Transitivity Alternations: A Layering Approach. Oxford: Oxford University Press.

Bosse, Solveig, Benjamin Bruening and Masahiro Yamada. 2012. Affected experiencers. Natural Language \& Linguistic Theory 30: 1185-1230.

Bruening, Benjamin. 2010. Ditransitive asymmetries and a theory of idiom formation. Linguistic Inquiry 41: 519-562.

Collins, Chris. 2002. Eliminating labels. In Samuel David Epstein and T. Daniel Seely [eds.] Derivation and Explanation in the Minimalist Program, 42-64. Oxford: Blackwell.

Den Dikken, Marcel. 2010. Directions from the GET-GO: On the syntax of manner-of-motion verbs in directional constructions. Catalan Journal of Linguistics 9: 23-53.

Harley, Heidi. 2011. A Minimalist Approach to Argument Structure. In Cedric Boeckx [ed.] The Oxford Handbook of Linguistic Minimalism, 427-448. Oxford: Oxford University Press.

Harley, Heidi. 2013. External arguments and the Mirror Principle: On the distinctness of Voice and v. Lingua 125: 34-57.

Haselbach, Boris and Marcel Pitteroff. 2014. A morphological case approach to PPs. Manuscript, University of Stuttgart.

Haspelmath, M. 1993. More on the typology of inchoative/causative verb alternations. In B. Comrie and M. Polinsky [eds.] Causatives and Transitivity, 87-120. Amsterdam: John Benjamins.

Horn, Laurence R. 2013. I love me some datives: Expressive meaning, free datives, and Fimplicature. In Daniel Gutzmann and Hans-Martin Gärtner [eds.] Beyond Expressives: Explorations in Use-Conditional Meaning, 151-199. Leiden/Boston: Brill.

Jackendoff, Ray. 1992. Babe Ruth homered his way into the hearts of America. In Eric Wehrli and Tim Stowell [eds.] Syntax and the Lexicon, 155-178. New York: Academic Press.

Landau, Idan. 1999. Possessor raising and the structure of VP. Lingua 107: 1-37.

Legate, Julie Anne. 2014. Voice and v: Lessons from Acehnese. MIT Press.

Maling, Joan, and Sigríður Sigurjónsdóttir. 2002. The 'new impersonal' construction in Icelandic. Journal of Comparative Germanic Linguistics 5: 97-142.

Marantz, Alec. 1992. The way-construction and the semantics of direct arguments in English: A reply to Jackendoff. In Eric Wehrli, and Tim Stowell [eds.] Syntax and the Lexicon, 179-188. New York: Academic Press.

Marantz, Alec. 2009a. Resultatives and re-resultatives: Direct objects may construct events by themselves. Paper presented at the University of Pennsylvania Linguistics Speaker Series.

Marantz, A. 2009b. Roots, re-, and affected agents: Can roots pull the agent under little v? Talk given at Roots workshop, Universität Stuttgart, Germany, June 10-13.

Marantz, Alec. 2013. Verbal argument structure: events and participants. Lingua 130: 152-168.

Mateu, Jaume. 2005. Arguing our way to the direct object restriction on English resultatives. Journal of Comparative Germanic Linguistics 8: 55-82.

Miyagawa, Shigeru. 1989. Structure and Case Marking in Japanese. San Diego, CA: Academic Press.

Myler, Neil. 2014. Building and Interpreting Possession Sentences. Doctoral Dissertation, NYU.

Oehrle, Richard, and Hiroko Nishio. 1981. Adversity. In Ann K. Farmer and Chisato Kitagawa [eds.] Proceedings of the Arizona Conference on Japanese Linguistics, 163-187. Tucson: University of Arizona Linguistics Circle.

Pylkknen, Liina. 2008. Introducing Arguments. Cambridge: MIT Press. 
Ramchand, Gillian Catriona. 2008. Verb Meaning and the Lexicon: A First-Phase Syntax. Cambridge: Cambridge University Press.

Schäfer, Florian. 2008. The Syntax of (Anti-)Causatives. Philadelphia: John Benjamins.

Sigurðsson, Halldór Ármann. 1989. Verbal Syntax and Case in Icelandic. Doctoral Dissertation, Lund University.

Sigurðsson, Halldór Ármann. 2012. Minimalist C/case. Linguistic Inquiry 43: 191-227.

Sigurjónsdóttir, Sigríður. 1992. Binding in Icelandic: Evidence from Language Acquisition. Doctoral Dissertation, UCLA.

Svenonius, Peter. 2003. Limits on P: filling in holes vs. falling in holes. Nordlyd 31: 431-445.

Svenonius, Peter. 2007. Adpositions, particles and the arguments they introduce. In Eric Reuland, Tanmoy Bhattacharya, and Giorgos Spathas [eds.] Argument Structure, 63-103. Philadelphia: John Benjamins.

Talmy, Leonard. 1985. Lexicalization patterns: Semantic structure in lexical forms. In Timothy Shopen [ed.] Language Typology and Syntactic Description, 57-149. Cambridge: Cambridge University Press.

Thráinsson, Höskuldur. 2007. The Syntax of Icelandic. Cambridge: Cambridge University Press.

Wood, Jim. 2014. Reflexive -st verbs in Icelandic. Natural Language \& Linguistic Theory 32: 13871425.

Wood, Jim. 2015. Icelandic Morphosyntax and Argument Structure . Dordrecht: Springer..

Wood, Jim and Einar Freyr Sigurðsson. 2014. 'Get'-passives and case alternations: The view from Icelandic. In Robert E. Santana-LaBarge [ed.] Proceedings of the 31st West Coast Conference on Formal Linguistics, 493-503. Somerville, MA: Cascadilla Proceedings Project. 